\title{
The Inhibition of Proliferation and Invasion of Human Colon Carcinoma Cell Line (Caco-2 cells) by Cell-free Supernatants from Lactobacillus Rhamnosus and Lactobacillus Acidophilus
}

\author{
Ameneh Shokati \\ Tarbiat Modares University \\ Masoud Soleimani \\ Tarbiat Modares University \\ Saeid Abroun ( $\square$ abroun@modares.ac.ir) \\ Tarbiat Modares University
}

\section{Research Article}

Keywords: Lactobacillus, Colon cancer, Probiotic, Invasion assay, Metastasis

Posted Date: January 27th, 2021

DOl: https://doi.org/10.21203/rs.3.rs-148685/v1

License: (9) This work is licensed under a Creative Commons Attribution 4.0 International License. Read Full License 


\section{Abstract}

Background: The epidemiological studies indicated that colorectal cancer is one of the most common types of cancer in the world and is considered a leading cause of cancer-related death. The present study aimed to investigate the inhibitory effect of lactobacillus acidophilus supernatant (LAS) and lactobacillus rhamnosus supernatant (LRS) on the growth and invasiveness of the human colon carcinoma cell line (Caco2) in-vitro.

Methods: In this experimental study, the anti-proliferative activity and anti-invasion potential of LAS and LRS were determined by MTT and transwell chambers assays, respectively. The expression of mitochondrial membrane potential-9 (MMP-9) and matrix metalloproteinase-12 (MMP12) genes were analyzed by real-time PCR.

Results: The results indicated that supernatants of these two lactobacilli had cytotoxic effects on Caco-2 cells at a concentration of $25 \% \mathrm{~V} / \mathrm{v}$ and higher. Thus, the minimum concentrations ( $25 \% \mathrm{~V} / \mathrm{V})$ of supernatants were chosen for further experiments. LAS and LRS could significantly suppress the invasiveness of Caco-2 cells. Also, the expression of MMP12 was significantly increased in Caco-2 cells when treated with LAS, whereas LRS had no significant effect on the invasive capacity and the gene expression levels of MMP12. The expression of MMP-9 was statistically decreased in Caco2 cells treated with LAS and LRS $(P<0.00001)$.

Conclusion: In general, it was shown that LAS and LRS exert anti-cancer activity against the growth, invasion, and metastasis of Caco2 cells in-vitro. It seems that these two bacteria could be used as prophylactic and therapeutic agents for the prevention and treatment of colorectal cancer.

\section{Introduction}

According to epidemiological studies, colorectal cancer is ranked as the fourth leading cause of mortality in the world [1]. The incidence of colorectal cancer is higher in western countries and rapidly increasing in developed Asian countries [2]. There are various risk factors associated with colorectal cancer, including external factors, such as poor diet, alcohol consumption, tobacco use, and sedentary work, as well as internal factors, such as genetic predisposition, hormone, and immunological imbalances [3]. Recently, the role of gut microbiota in the development of colorectal cancer has attracted much attention, and numerous studies have indicated that the homeostasis of gut microbiota is closely related to the risk factors mentioned earlier [4-6]. It has been reported that abnormal gut microbiota leads to the emergence of different pathophysiological events associated with numerous diseases, such as colorectal cancer [5, 7]. However, the precise mechanism of microbiota in the development of colorectal cancer is still opaque. Among the factors mentioned above, diet plays an essential role in the emergence of colorectal cancer [3, 8].

Probiotics are vital microorganisms in a healthy human microbiota environment [9]. Lactobacillus species is one of the most commonly used probiotics. Lactic acid bacteria (LAB) exert health-promoting activity 
closely associated with the suppression of allergic responses as well as anti-inflammatory and anti-tumor effects [10-12]. As members of the gut microbiota, lactic acid bacteria (LAB), especially Lactobacillus, exert health benefits for the host when administered in adequate amounts [13]. Several lines of evidence demonstrated that the supplementation of LAS could act as a prophylactic strategy for the prevention and cure of colorectal cancer as a result of their probiotic properties [14-17].

Nevertheless, the beneficial role of LAB in the inhibition of colorectal cancer progression and their effects on tumor microenvironments remain largely unknown. A number of investigations suggested that $L A B$ exert anti-neoplastic activity by promoting the immunity or modulation of immune responses [18]. They also enhance the DNA repair process [19], stimulate programmed cell death, and inhibit the proliferation of colon cancer cells [20]. Although accumulative evidence supports the role of probiotic LAB in the prevention of the early stages of the development of colon cancer, little is known about the effect of $L A B$ role in later stages of colorectal cancer, especially metastasis.

Matrix metallopeptidases belong to the matrix metalloproteinase (MMP) family, whose activity is dependent on the zinc ion and they are categorized as protolithic enzymes that are responsible for the remodeling and the degradation of the components of the extracellular matrix (ECM) [21, 22]. Proteins incorporated into the ECM contribute to the regulation of cancer cell functions and tumor microenvironments. Also, it has been shown that abnormal ECM deposition leads to tissue remodeling and progression of tumorigenesis [23]. MMPs are able to digest proteins present in the ECM, such as gelatin, elastin, and collagen I, IV, and V.

These types of proteins can eradicate the structural barriers and facilitate the migration of cells. Besides, by hydrolyzing the extracellular proteins released by MMPs, they are capable of changing the activity of numerous signal peptides, including cytokines, growth factors, and chemokines. Increased activity or expression of MMPs is markedly associated with higher invasiveness and the ability to metastasize in almost all types of human cancer and poor prognosis [24].

The MMP-9 protein belongs to the matrix metalloproteinase family, and it is able to digest all extracellular matrix proteins. The levels of MMP-9 level have been shown as a biological index for poor prognosis in colorectal cancer, along with other types of cancer, such as cervical and breast cancer [25]. MMP-12, also named metalloelastase, does not belong to the MMP family; however, it has been demonstrated that this protein can degrade a broad range of substrates. A group of studies has shown that MMP-12 is mainly expressed in macrophages and its protective roles in the prevention of colorectal cancer.

To the best of our knowledge, no study was conducted on the role of cell-free supernatants of probiotics in the prevention and elimination of human colon carcinoma cell line (Caco-2). Thus, cell death, invasion rate, and the indices of metastasis, such as MMP-9 and MMP-12, were measured in Caco-2 cells.

\section{Materials And Methods}


DMEM (Dulbecco's Modified Eagle's medium), extracellular matrix (ECM), Lactic acid, Trypan blue, penicillin, ampicillin, streptomycin, and MTT (3-(4,5-Dimethylthiazol-2-yl)-2,5-Diphenyltetrazolium Bromide) were purchased from Sigma-Aldrich (Merk). Fetal Bovine Serum (FBS) was procured from Gibco (Thermo Fisher Scientific- US). The real-time PCR assay kit was procured from Amplicon.

\subsection{Bacterial strains and culture medium}

The following lactobacillus strains, namely L. acidophilus, L. rhamnose, were stored in the De Man, Rogosa, and Sharpe (MRS) broth medium (MRS broth, Scharlau, Spain) ( $\mathrm{pH}=6.5$, Merck, Germany) supplemented with $20 \%(\mathrm{v} / \mathrm{v})$ glycerol at $-80^{\circ} \mathrm{C}$. Before the experiments, each strain was cultured in MRS broth and incubated under the anaerobic condition at $37^{\circ} \mathrm{C}$.

\subsection{Preparation of cell-free supernatant (CSF)}

For preparing cell-free supernatant (CSF), bacterial cells $\left(10^{9} \mathrm{CFU} / \mathrm{ml}\right)$ at the logarithmic phase of growth (after 24 and $48 \mathrm{~h}$ ) were centrifuged at $5000 \mathrm{~g}$ for $15 \mathrm{~min}$, and the supernatants were filtered using a 0.22 $\mu \mathrm{m}$ bacterial filter. Cell-free supernatant was adjusted to $\mathrm{pH} 7.4$ using bicarbonate buffer. Afterward, various concentrations $(0,5,10,15,20,25,30,35,40,45$, and $50 \%$ from supernatant) were prepared for the cell viability assay.

\subsection{Cell proliferation, migration and invasion assays}

This experiment focused on analyzing the effects of $L$. acidophilus, $L$. rhamnose supernatants on the growth inhibition of Caco2 cells (NCBI C139, Pasteur Institute of Tehran, Iran). The yellow tetrazolium salt, 3-(4,5-Dimethylthiazol-2-yl)-2,5-diphenyltetrazolium bromide (MTT) is enzymatically reduced by viable cells, producing insoluble formazan crystals with purple color. So, such a change in the color of the product could be quantifiable by spectrophotometry. Briefly, $4 \times 10^{4}$ cells/well were seeded onto a 96 -well plate, and the cells were cultured overnight at $37^{\circ} \mathrm{C}$ in a $\mathrm{CO} 2$ incubator $(5 \% \mathrm{CO} 2)$ to adhere to the bottom of the wells. Then, cells were treated with different concentrations of lactobacillus culture supernatants (24h and $48 \mathrm{~h})(0-50 \% \mathrm{~V} / \mathrm{V})$. The results were subsequently analyzed after 24,48 , and $72 \mathrm{~h}$. The MTT solution $(0.5 \mathrm{mg} / \mathrm{ml})$ was added to the wells, followed by incubation at $37^{\circ} \mathrm{C}$ for $4 \mathrm{~h}$. The precipitated formazan crystals were solubilized by adding $100 \mu \mathrm{l}$ of DMSO, and the optical absorbance of the wells was measured at $570 \mathrm{~nm}$, using an ELISA reader (Model 680, BIO-RAD, Hercules, CA, USA). The inhibition rate $(\mathrm{IR})$ was evaluated using the following equation:

Inhibition ratio $(\%)=1-O D_{\text {exp }} / O D_{\text {con }} \times 100$

Where $O D_{\text {exp }}$ and $O D_{\text {con }}$ are the optical absorbance values of treated and untreated cells, respectively.

Cell invasion was assessed using the Transwell method. To this aim, a total of $2 \times 10^{4}$ cells were cultured in the DMEM medium at the top of the transwell membrane chamber (Costar; Corning, 8- $\mu$ m pore size). In the bottom of the chamber, the cell culture medium supplemented with $10 \%$ FBS was added (Fig. 1). The migration assay was carried out after 36 hours at $37^{\circ} \mathrm{C}$ in $5 \% \mathrm{CO}_{2}$ humidified incubator. The cells grown at 
the upper surface of the membrane were carefully scraped off after the incubation period. Cells migrated to the bottom surface were fixed in $100 \%$ methanol for $5 \mathrm{~min}$. Then, the cells were stained with crystal violet staining solution for 2 min. Afterward, cells were counted under a light microscope at different random fields at $\times 300$ magnifications. The number of Caco- 2 cells was expressed as the mean number of cells per group.

\subsection{RNA extraction, cDNA synthesis, and real-time quantitative reverse transcription-polymerase chain reaction}

Total RNA was isolated from treated and untreated cells using the RNeasy Mini Kit (Hilden, Germany). The quality and quantity of the extracted RNA were spectrophotometrically determined using a Nanodrop instrument (Thermo Scientific, USA). The SYBR Premix Ex Taq 11 reagent kit (Takara Bio, Japan) was used for the reverse-transcription of RNA, and then the mRNA expression of target genes was analyzed using qRT-PCR. The gene expression analysis of purified mRNA genes, including MMP12, and MMP9 was performed using Applied Biosystems Step One Real-Time PCR (Thermo Fisher). The master mix reaction solution used for real-time PCR comprised of $250 \mathrm{ng}$ CDNA, 2x master mix (10 $\mu \mathrm{l}), 10 \mathrm{pmol}$ of each primer pairs adjusted by $\mathrm{ddH}_{2} \mathrm{O}$ up to final reaction of $10 \mu \mathrm{l}$. The sequences of primers were designed by the NCBI PRIMER BLAST tool. The primers used in real-time PCR were as follows: MMP9 forward primer: AAGGATGGGAAGTACTGGCG, reverse primer: GCTCCTCAAAGACCGAGTCC, MMP12 forward primer: TTTGGTGGTTTTTGCCCGTG, reverse primer: GGAACAAGTTTGTGCCTCCTG, and $\beta$-Actin (reference gene) forward primer: TGAAGATCAAGATCATTGCTCCC, reverse primer: AGTCATAGTCCGCCTAGAAGC. The thermal cycling program was initiated by cDNA denaturation at $95^{\circ} \mathrm{C}$ for $30 \mathrm{~s}$, followed by 40 cycles of $95^{\circ} \mathrm{C}$ for 5 seconds and $61^{\circ} \mathrm{C}$ for 34 seconds. The experiments were carried out in triplicate for each target gene. In order to examine the specificity of primers used, as well as the absence of primer dimmer, the melting curve analysis was conducted after each run of amplification.

\subsection{Statistical Analysis}

The obtained values are expressed as the means and standard deviation (means \pm SD). The difference between the experimental groups and the untreated group were analyzed by two-tailed Student T-test. The level of statistical significance was set at $p<0.05$.

\section{Results}

\subsection{Cytotoxic effect of L. acidophilus and L. rhamnosus strain culture supernatants on Caco2 cell growth}

The cells were treated with different concentrations of lactobacillus culture supernatants $(0-50 \% \mathrm{~V} / \mathrm{V})$ collected after $24 \mathrm{~h}$ and $48 \mathrm{~h}$ of the incubation period. The results were subsequently analyzed after 24,48 , and $72 \mathrm{~h}$. Cell growth inhibitory effects were determined by the MTT assay (Fig. 2). The results demonstrated that LAS and LRS (collected supernatants after 24 and $48 \mathrm{~h}$ of the incubation periods) had a 
significant inhibitory effect on Caco2 cell proliferation in comparison with cells treated with the MRS solutions or those left untreated. LAS and LRS inhibited $50 \%$ of the cell proliferation at a concentration of $25 \% \mathrm{~V} / \mathrm{V}$ (IC50) after $24 \mathrm{~h}$. Also, the cell viability was significantly reduced at $20 \%$ and $25 \%$ concentrations of LAS and LRS after $72 \mathrm{~h}$. The obtained results indicated that LRS collected after $48 \mathrm{~h}$ had more cytotoxic activity against the Caco 2 cell line compared with those collected after $24 \mathrm{~h}$. There was no significant difference in cell viability when Caco- 2 cells were treated with LAS after $24 \mathrm{~h}$ and $48 \mathrm{~h}$.

\subsection{Inhibition of invasiveness by $L$. acidophilus supernatant}

The cell invasion analysis was performed in the matrigel basement membrane using a transwell system, as described in the section of "Materials and methods." In this method, cells that migrated into the lower surface of the membrane were fixed and then stained (Fig. 3). The percentages of migration and invasion of cells were significantly lower when the cells were incubated with LAS $(P<0.01)$ and LRS $(P<0.05)$ after $36 \mathrm{~h}$ compared with cells treated with the MRS solution.

\subsection{Effects of LAS and LRS on the expression of MMP-9 and MMP-12 genes in Caco2 cells}

In order to analyze the effect of LAS and LRS on the expression of MMP-9 and MMP-12 genes, Caco2 cells were cultured in the presence of LAS and LRS at a concentration of $25 \%$ for $36 \mathrm{~h}$, and then the total RNA of cells was isolated, and RT-PCR was performed as described earlier. As shown in Fig. 4A, the expression of MMP-12 was significantly increased in cells treated with LAS, while LRS had no significant effect on the expression of the MMP12 gene when compared with cells treated with the MRS solution. As depicted in Fig. 4B, the expression of MMP-9 was significantly decreased in Caco2 cells treated with LRS and LAS compared with the MRS-treated Caco-2 cells.

\section{Discussion}

The invasion of primary tumors into distant organs such as the lungs and liver is considered the principal cause of mortality in patients afflicted with colorectal cancer [26]. Unfortunately, a vast majority of patients with colorectal cancer are diagnosed at the advanced stages of the disease, especially when the initial tumors invaded other organs. This phenomenon reduces the survival rate of patients by $10 \%$. Alternatively, all therapeutic options, including chemotherapy, surgery, and radiotherapy, can remarkably affect the quality of life of patients. It has been shown that both radiotherapy and chemotherapy have serious adverse effects on the human and mainly emerged as gastrointestinal toxicity, namely mucositis, enteritis, diarrhea, nausea, and vomiting [27]. Therefore, it seems prophylactic strategies and alternative treatments are needed to prevent the emergence of colorectal cancer.

In the present study, the impact of two probiotic Lactobacillus sp., namely L. acidophilus and L.rhamnosus, on the inhibition of the growth and metastasis of Caco2 cancer cells was determined through analyzing the cell invasion assay in-vitro and the expression of MMP-9 and MMP-12 genes. 
Studies indicated that the proteolytic activity of the MMP-9 enzyme contributes to the digestion of the extracellular matrix in the colon, facilitating the cell invasion process during metastasis [28-31]. Conversely, evidence showed that the expression of MMP-12, which is a metalloelastase enzyme, has inhibitory effects on the growth and proliferation of colorectal cancer cells, and it is associated with increased survival of patients with colorectal cancer [32].

We showed that LAS and LRS had a significant effect on the viability of Caco2 cells compared with those treated with the MRS medium (control). Also, our results revealed that LAS and LRS containing secreted bioactive compounds significantly reduced the invasion of metastatic colon cancer cells in-vitro (Figure 3), as shown by decreased expression of MMP-9 (Figure 4A). Furthermore, LAS increased the expression levels of MMP-12 (Figure 4B), while LRS had no effect on MMP-12 expression. To the best of our knowledge, the current research is the first study reporting that released bioactive compounds from $L$. acidophilus and L. rhamnosus can regulate the expression levels of MMP-9 and MMP-12 genes in Caco-2 cells, suggesting their potential role in the inhibition of colon cancer cell invasion.

It is now known that MMPs have detrimental roles in metastasis of colon cancer, promoting the invasion of primary tumors through the digestion of collagen in the ECM $[28,29]$. It has been shown that the MMP-9 enzyme has proteolytic activity, participating in reconstruction and breakdown of the ECM, a phenomenon observed in the invasion and metastasis of colorectal cancer. The MMP-9 protein is capable of regulating the tumor microenvironment and increasing the levels of vascular endothelial growth factor (VEGF), which is involved in the angiogenesis process [33]. Also, MMP-9 effectively contributes to the formation of early metastatic niches [34]. A number of preclinical analyses demonstrated that the selective inhibition of MMP-9 is able to decrease tumor proliferation and metastasis rates in colorectal cancer. It can also induce programmed cell death in pancreatic cancer cells [35,36]. Escamilla and colleagues showed that cell-free supernatants extracted from probiotic Lactobacillus rhamnosus $G G$ led to a marked reduction in the growth and invasion of HCT-116 cells, thereby diminishing the expression and activity of MMP-9 [20].

On the other hand, a large body of evidence indicates that the inhibition of MMP-12 has deleterious effects on the treatment course of cancer [37,38]. While elevated expression of MMP-12 has been reported in patients diagnosed with CRC, its expression level has been higher in patients with no liver metastasis compared with those with liver metastasis [39]. Besides, the expression of MMP-12 is able to lower the expression rate of VEGF and increase the expression of angiostatin, which is an endogenous inhibitor of the angiogenesis process [40]. Consistent with these statements, a number of investigations demonstrated that the expression of MMP-12 is associated with increased overall survival of patients and reduced tumor growth $[41,42]$. The degree of MMP-12 expression has been conversely attributed to the metastasis process of primary colon cells [39]. Our findings showed that the effect of LAS on the cell invasion and proliferation was more pronounced than that of LRS. This may be due to the amplifying role of LAS in the expression of MMP-12. In addition to the anti-proliferative, pro-apoptotic, and anti-metastatic effects of lactobacilli [43-45], our results showed that L. acidophilus and L. rhamnosus also have remarkable anti-proliferative and anti-metastatic effects on colorectal cancer cells. 
A number of studies demonstrated the relationship between a diet enriched with Lactobacillus and reduced risk of colon cancer [46]. Several studies, in vitro and in vivo, revealed that probiotics modulate cancer cells, like Caco2 cell line, proliferation and apoptosis [47-49]. Furthermore, it is now known that probiotics have various properties, including radio-protective, antioxidant, and antagonistic activity, as well as toxin neutralization. They are able to improve the intestinal microbial environment and immune system response [50]. Thus, they could be used as an alternative therapy instead of using invasive treatments, such as radiotherapy and chemotherapy.

\section{Conclusions}

In conclusion, this study revealed that the expression level of MMP-9 gene, as indices of metastasis, are influenced by the cell-free supernatants extracted from L. acidophilus and L. rhamnosus. Moreover, the modulation of the MMP-12 gene by L. acidophilus resulted in the anti-invasion activity of Caco-2 cells.

Several lines of evidence showed the significance of probiotic balance in the maintenance of homeostasis, which paves the way to achieve optimal cancer therapy. Recent studies suggest the application of probiotics in cutting-edge cancer therapies. Clinical studies and animal models performed on L. Acidophilus and L. Rhamnosus suggest the possibility of utilizing such probiotics as alternative approaches to prevent metastasis and cure cancer.

Altogether, regarding the above findings, further research is required to characterize the precise mechanism of action of bioactive factors in probiotic-containing functional foods. This provides insight into seeking preventive strategies to combat cancer cell proliferation and invasion.

\section{List Of Abbreviations}

Colon carcinoma cell line Caco-2

DMEM Dulbecco's Modified Eagle's medium

ECM Extracellular matrix

FBS Fetal bovine serum

Lactic acid bacteria LAB

lactobacillus acidophilus supernatant LAS

lactobacillus rhamnosus supernatant LRS

Matrix metalloproteinase MMP

Mitochondrial membrane potential-9 MMP-9 


\section{Declarations}

\section{- Ethics approval and consent to participate}

At the time of this study had been done, study on cell line did not need to ethic Committee permission at my university.

\section{- Consent for publication}

Not applicable.

\section{- Availability of data and materials}

The original data are available upon reasonable request to the corresponding author.

\section{- Competing interests}

The authors declare any competing interests.

\section{- Funding}

No any funding supported this study.

\section{- Authors' contributions}

AS, MS, and SA contributed to the concept of the manuscript. AS, MS, and SA were responsible for the reference selection and writing of the manuscript. AS prepared figures 1-4. All authors read and approved the final manuscript.

\section{- Acknowledgements}

The authors have special thanks to Department of Hematology Lab Director.

\section{References}

1. Gandomani HS, Yousefi SM, Aghajani M, Mohammadian-Hafshejani A, Tarazoj AA, Pouyesh V, et al. Colorectal cancer in the world: incidence, mortality and risk factors. Biomed Res Ther. 2017;4:1656.

2. Arnold M, Sierra MS, Laversanne M, Soerjomataram I, Jemal A, Bray F. Global patterns and trends in colorectal cancer incidence and mortality. Gut. 2017;66:683-91. 
3. Society AC. Shifts of Faecal Microbiota during Sporadic Colorectal Carcinogenesis [Internet]. Am. Cancer Soc. 2020. p. 1-52. Available from:

http://www.cancer.org/acs/groups/content/@nho/documents/document/caff2007pwsecuredpdf.pdf

4. Ehsan A, Mahmood K, Khan YD, Khan SA, Chou KC, Tilg H, et al. The Role of the Gut Microbiome in Colorectal Cancer. Clin Colon Rectal Surg [Internet]. Springer US; 2018;31:1-16. Available from: https://doi.org/10.1016/j.ccell.2018.03.004

5. Tilg H, Adolph TE, Gerner RR, Moschen AR. The Intestinal Microbiota in Colorectal Cancer. Cancer Cell [Internet]. Elsevier Inc.; 2018;33:954-64. Available from: https://doi.org/10.1016/j.ccell.2018.03.004

6. Ehsan A, Mahmood K, Khan YD, Khan SA, Chou KC. A Novel Modeling in Mathematical Biology for Classification of Signal Peptides. Sci Rep [Internet]. Springer US; 2018;8:1-16. Available from: http://dx.doi.org/10.1038/s41598-018-19491-y

7. Mori G, Rampelli S, Orena BS, Rengucci C, De Maio G, Barbieri G, et al. Shifts of Faecal Microbiota during Sporadic Colorectal Carcinogenesis. Sci Rep. 2018;8:1-11.

8. Davis CD, Milner JA. Gastrointestinal microflora, food components and colon cancer prevention. J. Nutr. Biochem. 2009. p. 743-52.

9. Roy S, Trinchieri G. Microbiota: A key orchestrator of cancer therapy. Nat Rev Cancer [Internet]. Nature Publishing Group; 2017;17:271-85. Available from: http://dx.doi.org/10.1038/nrc.2017.13

10. Ding C, Tang W, Fan X, Wu G. Intestinal microbiota: A novel perspective in colorectal cancer biotherapeutics. Onco Targets Ther. 2018;11:4797-810.

11. Kahouli I, Malhotra M, Westfall S, Alaoui-Jamali MA, Prakash S. Design and validation of an orally administrated active L. fermentum-L. acidophilus probiotic formulation using colorectal cancer Apc Min/+ mouse model. Appl Microbiol Biotechnol [Internet]. Applied Microbiology and Biotechnology; 2017;101:1999-2019. Available from: http://dx.doi.org/10.1007/s00253-016-7885-x

12. El-Deeb NM, Yassin AM, Al-Madboly LA, El-Hawiet A. A novel purified Lactobacillus acidophilus 20079 exopolysaccharide, LA-EPS-20079, molecularly regulates both apoptotic and NF-KB inflammatory pathways in human colon cancer. Microb Cell Fact [Internet]. BioMed Central; 2018;17:1-15. Available from: https://doi.org/10.1186/s12934-018-0877-z

13. Nk B, Jang H, Lee K, Kim D. nutrients The Preventive and Curative E ff ects of Lactobacillus. 2019;

14. Eslami M, Yousefi B, Kokhaei P, Hemati M, Nejad ZR, Arabkari V, et al. Importance of probiotics in the prevention and treatment of colorectal cancer. J Cell Physiol. 2019;234:17127-43.

15. Pellegrino MS, Frola ID, Natanael B, Gobelli D, Nader-Macias MEF, Bogni Cl. In Vitro Characterization of Lactic Acid Bacteria Isolated from Bovine Milk as Potential Probiotic Strains to Prevent Bovine Mastitis. Probiotics Antimicrob Proteins. Probiotics and Antimicrobial Proteins; 2019;11:74-84.

16. Zinatizadeh N, Khalili F, Fallah P, Farid M, Geravand M, Yaslianifard S. Potential preventive effect of Lactobacillus acidophilus and Lactobacillus plantarum in patients with polyps or colorectal cancer. Arq Gastroenterol. 2018;55:407-11.

17. Ambalam P, Raman M, Purama RK, Doble M. Probiotics, prebiotics and colorectal cancer prevention. Best Pract Res Clin Gastroenterol [Internet]. Elsevier Ltd; 2016;30:119-31. Available from: 
http://dx.doi.org/10.1016/j.bpg.2016.02.009

18. Casas-Solís J, Huizar-López M del R, Irecta-Nájera CA, Pita-López ML, Santerre A. Immunomodulatory Effect of Lactobacillus casei in a Murine Model of Colon Carcinogenesis. Probiotics Antimicrob Proteins [Internet]. Probiotics and Antimicrobial Proteins; 2020;12:1012-24. Available from: http://link.springer.com/10.1007/s12602-019-09611-z

19. Huang S, Gaucher F, Cauty C, Jardin J, Loir Y Le, Jeantet R, et al. Growth in hyper-concentrated sweet whey triggers multi stress tolerance and spray drying survival in Lactobacillus casei BL23: From the molecular basis to new perspectives for sustainable probiotic production. Front Microbiol. 2018;9:112.

20. Escamilla J, Lane MA, Maitin V. Cell-free supernatants from probiotic lactobacillus casei and lactobacillus rhamnosus GG decrease colon cancer cell invasion in vitro. Nutr Cancer. 2012;64:871-8.

21. Lu P, Takai K, Weaver VM, Werb Z. Extracellular Matrix degradation and remodeling in development and disease. Cold Spring Harb Perspect Biol. 2011;3.

22. Reviews N, Rev N, Accepted J, Accepted J, Rev N, Accepted J, et al. Effect of nanoparticles on expression and activity of matrix metalloproteinases. 2011;

23. Bonnans C, Chou J, Werb Z. Remodelling the extracellular matrix in development and disease. Nat Rev Mol Cell Biol [Internet]. Nature Publishing Group; 2014;15:786-801. Available from: http://dx.doi.org/10.1038/nrm3904

24. Galliera E, Tacchini L, Corsi Romanelli MM. Matrix metalloproteinases as biomarkers of disease: Updates and new insights. Clin Chem Lab Med. 2015;53:349-55.

25. Jonsson A, Hjalmarsson C, Falk P, Ivarsson ML. Stability of matrix metalloproteinase-9 as biological marker in colorectal cancer. Med Oncol [Internet]. Springer US; 2018;35:1-6. Available from: https://doi.org/10.1007/s12032-018-1109-4

26. Legolvan MP, Resnick M. Pathobiology of colorectal cancer hepatic metastases with an emphasis on prognostic factors. J Surg Oncol. 2010;102:898-908.

27. Agraib LM, Al-Shorman A, Salah S, Abu-Hijlih R, Abuhijla F. The effect of probiotics supplementation on the side effects of chemo radiotherapy for colorectal cancer: A literature review. Onkol i Radioter. 2020;14:1-9.

28. Leeman MF, Curran S, Murray GI. New insights into the roles of matrix metalloproteinases in colorectal cancer development and progression. J Pathol. 2003;201:528-34.

29. Mook ORF, Frederiks WM, Van Noorden CJF. The role of gelatinases in colorectal cancer progression and metastasis. Biochim Biophys Acta - Rev Cancer. 2004;1705:69-89.

30. Baker EA, Leaper DJ. Measuring gelatinase activity in colorectal cancer. Eur J Surg Oncol. 2002;28:24-9.

31. Okada N, Ishida H, Murata N, Hashimoto D, Seyama Y, Kubota S. Matrix Metalloproteinase-2 and -9 in Bile as a Marker of Liver Metastasis in Colorectal Cancer. Biochem Biophys Res Commun [Internet]. 2001;288:212-6. Available from: https://linkinghub.elsevier.com/retrieve/pii/S0006291X01957419 
32. Said AH, Raufman JP, Xie G. The role of matrix metalloproteinases in colorectal cancer. Cancers (Basel). 2014;6:366-75.

33. Herszényi L, Hritz I, Lakatos G, Varga MZ, Tulassay Z. The Behavior of matrix metalloproteinases and their inhibitors in colorectal cancer. Int J Mol Sci. 2012;13:13240-63.

34. Labelle M, Begum S, Hynes RO. Platelets guide the formation of early metastatic niches. Proc Natl Acad Sci U S A. 2014;111.

35. Marshall DC, Lyman SK, McCauley S, Kovalenko M, Spangler R, Liu C, et al. Selective allosteric inhibition of MMP9 is efficacious in preclinical models of ulcerative colitis and colorectal cancer. PLoS One. 2015;10:1-26.

36. Gao C chong, Gong B gang, Wu J ben, Cheng P guang, Xu H yong, Song D kun, et al. MMI-166, a selective matrix metalloproteinase inhibitor, promotes apoptosis in human pancreatic cancer. Med Oncol. 2015;32:1-9.

37. Decock J, Thirkettle S, Wagstaff L, Edwards DR. Matrix metalloproteinases: Protective roles in cancer. J Cell Mol Med. 2011;15:1254-65.

38. Overall $\mathrm{CM}$, Kleifeld $\mathrm{O}$. Validating matrix metalloproteinases as drug targets and anti-targets for cancer therapy. Nat Rev Cancer. 2006;6:227-39.

39. Asano T, Tada M, Cheng S, Takemoto N, Kuramae T, Abe M, et al. Prognostic Values of Matrix Metalloproteinase Family Expression in Human Colorectal Carcinoma. J Surg Res. 2008;146:32-42.

40. Shi H, Xu JM, Hu NZ, Wang XL, Mei Q, Song YL. Transfection of mouse macrophage metalloelastase gene into murine CT-26 colon cancer cells suppresses orthotopic tumor growth, angiogenesis and vascular endothelial growth factor expression. Cancer Lett. 2006;233:139-50.

41. Xu Z, Shi H, Li Q, Mei Q, Bao J, Shen Y, et al. Mouse macrophage metalloelastase generates angiostatin from plasminogen and suppresses tumor angiogenesis in murine colon cancer. Oncol Rep. 2008;20:81-8.

42. Yang W, Arii S, Gorrin-Rivas MJ, Mori A, Onodera H, Imamura M. Human macrophage metalloelastase gene expression in colorectal carcinoma and its clinicopathologic significance. Cancer. 2001;91:1277-83.

43. Tiptiri-Kourpeti A, Spyridopoulou K, Santarmaki V, Aindelis G, Tompoulidou E, Lamprianidou EE, et al. Lactobacillus casei exerts anti-proliferative effects accompanied by apoptotic cell death and upregulation of TRAIL in colon carcinoma cells. PLoS One. 2016;11:1-20.

44. Maghsood F, Johari B, Rohani M, Madanchi H, Saltanatpour Z, Kadivar M. Anti-proliferative and Antimetastatic Potential of High Molecular Weight Secretory Molecules from Probiotic Lactobacillus Reuteri Cell-Free Supernatant Against Human Colon Cancer Stem-Like Cells (HT29-ShE). Int J Pept Res Ther [Internet]. Springer Netherlands; 2020;26:2619-31. Available from: https://doi.org/10.1007/s10989-020-10049-z

45. Abedin-Do A, Taherian-Esfahani Z, Ghafouri-Fard S, Ghafouri-Fard S, Motevaseli E. Immunomodulatory effects of Lactobacillus strains: Emphasis on their effects on cancer cells. Immunotherapy. 2015;7:1307-29. 
46. Goldin BR, Gorbach SL. Effect of Lactobacillus acidophilus dietary supplements on 1,2dimethylhydrazine dihydrochloride-induced intestinal cancer in rats. J Natl Cancer Inst. 1980;64:2635.

47. Kim Y, Lee D, Kim D, Cho J, Yang J, Chung M, et al. Inhibition of proliferation in colon cancer cell lines and harmful enzyme activity of colon bacteria by Bifidobacterium adolescentis SPM0212. Arch Pharm Res. 2008;31:468-73.

48. Thirabunyanon M, Boonprasom P, Niamsup P. Probiotic potential of lactic acid bacteria isolated from fermented dairy milks on antiproliferation of colon cancer cells. Biotechnol Lett. 2009;31:571-6.

49. Altonsy MO, Andrews SC, Tuohy KM. Differential induction of apoptosis in human colonic carcinoma cells (Caco-2) by Atopobium, and commensal, probiotic and enteropathogenic bacteria: Mediation by the mitochondrial pathway. Int J Food Microbiol [Internet]. Elsevier B.V.; 2010;137:190-203. Available from: http://dx.doi.org/10.1016/j.ijfoodmicro.2009.11.015

50. Sugawara G, Nagino M, Nishio H, Ebata T, Takagi K, Asahara T, et al. Perioperative synbiotic treatment to prevent postoperative infectious complications in biliary cancer surgery: A randomized controlled trial. Ann Surg. 2006;244:706-14.

\section{Figures}

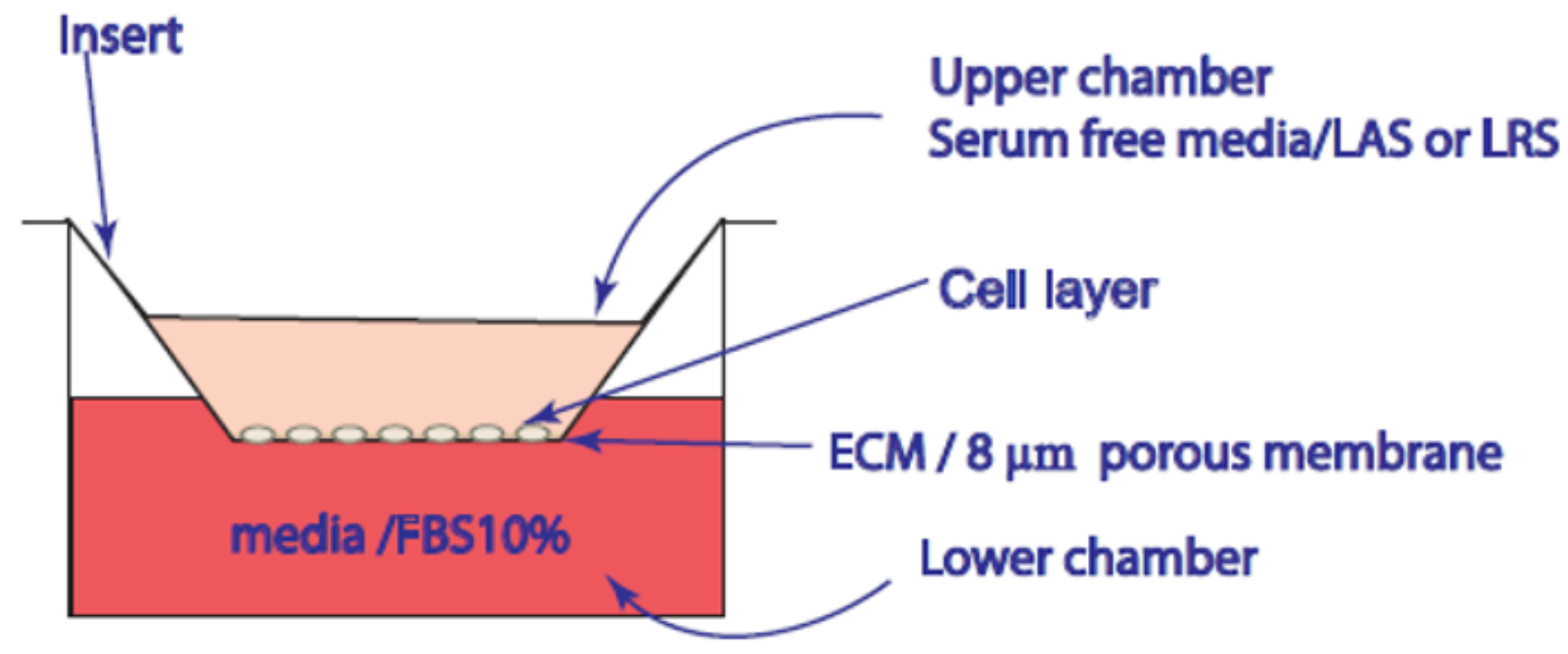

\section{Figure 1}

Transwell assay. In this method, cells that migrated into the lower surface of the membrane were fixed, stained and then counted. 
$A_{1}$

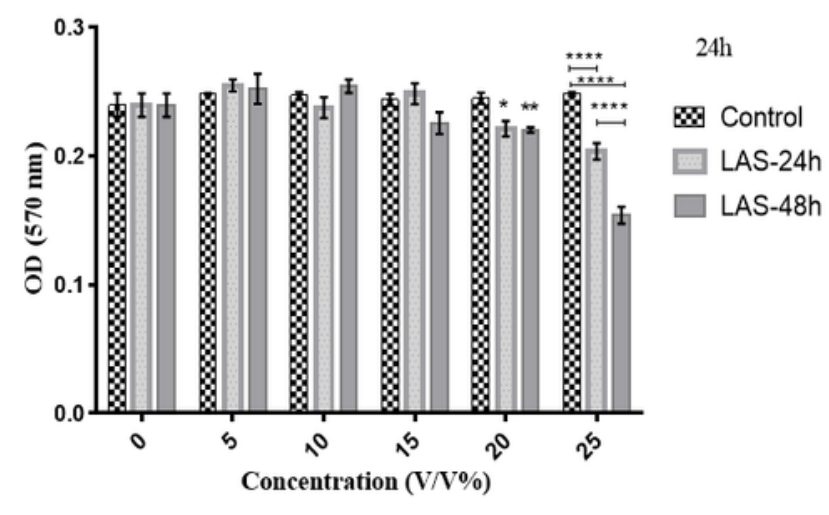

B1

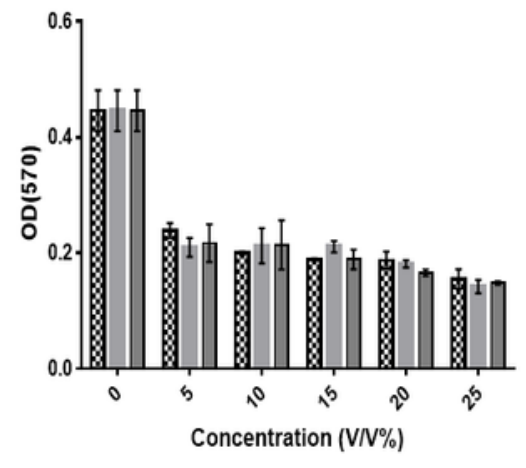

C1

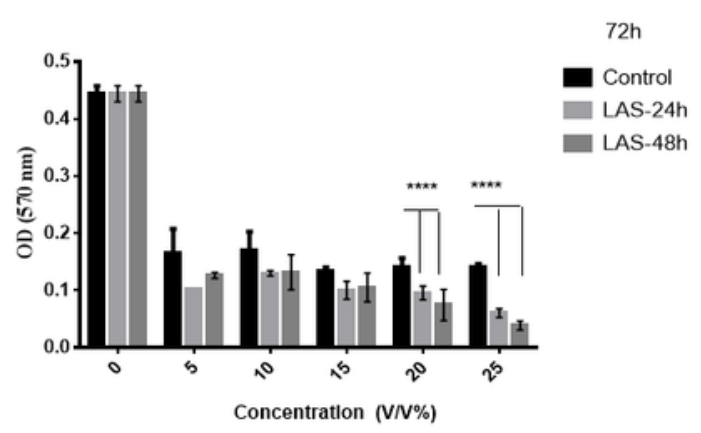

$A_{2}$

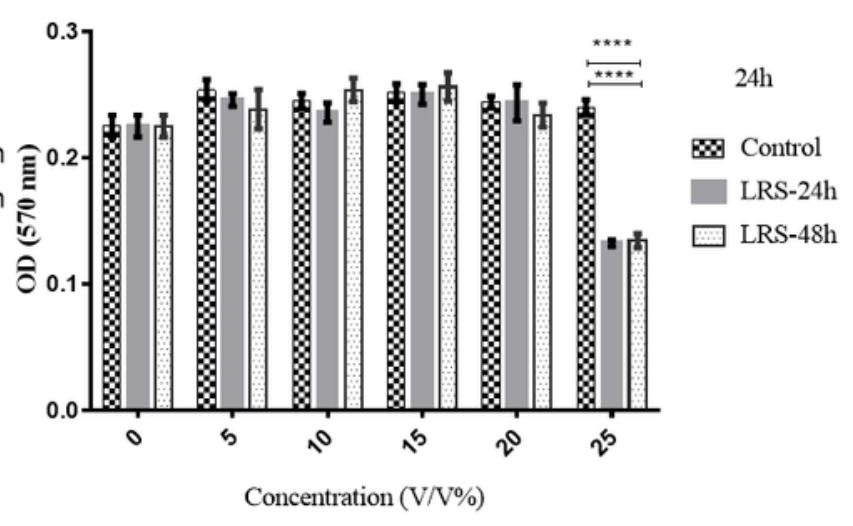

B2

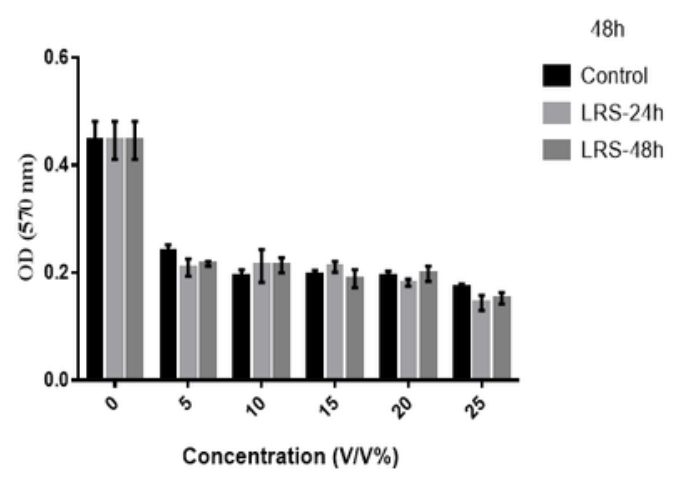

$\mathrm{C} 2$

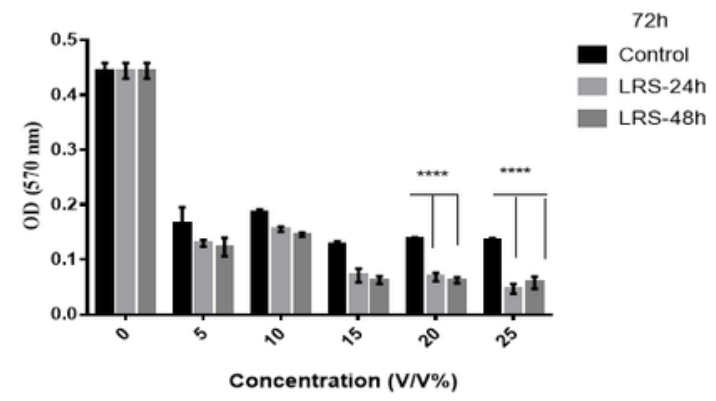

Figure 2

The MTT assay represents cytotoxicity effects of LRS, LAS, and MRS (collected after $24 \mathrm{~h}$ and $48 \mathrm{~h}$ ) with different concentrations on Caco2 cells; A1\&A2)) after 24h, B1\&B2) after 48h treatment, C1\&C2) after 72h treatment. LRS; Lactobacillus rhamnosus supernatant, LAS: Lactobacillus acidophilus supernatant. MRS; De Man Rogosa Sharpe. The mean value is represented with three separate experiments for each point. *; $P<0.05, * * ; P<0.01, * \star * ; P<0.001, \star \star \star \star * ; P<0.0001$. 


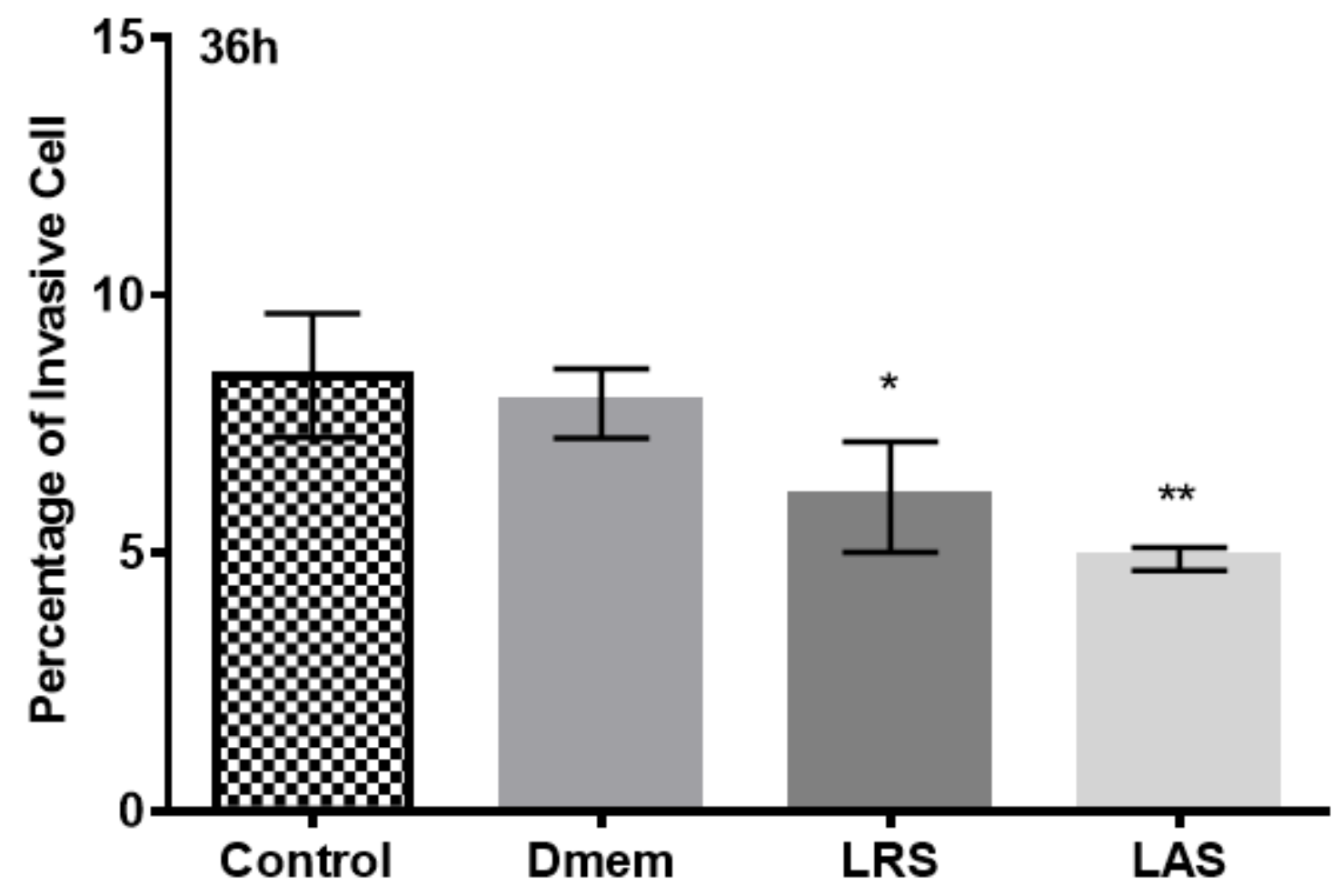

Figure 3

Cell migration/invasion assay in LRS- and LAS-treated Caco2 cells. Cells $(2 \times 104$ cells $/ \mathrm{ml})$ were treated with $25 \%$ concentrations of LAS and LRS for $36 \mathrm{~h}$. The mean number of cells from 6 random fields was expressed, and the values are represented as the mean \pm SD of three independent experiments. The asterisks indicate a statistically significant difference compared with control. Control: $25 \%$ Mrs. * $P<0.05$ and $* * P<0.01$.

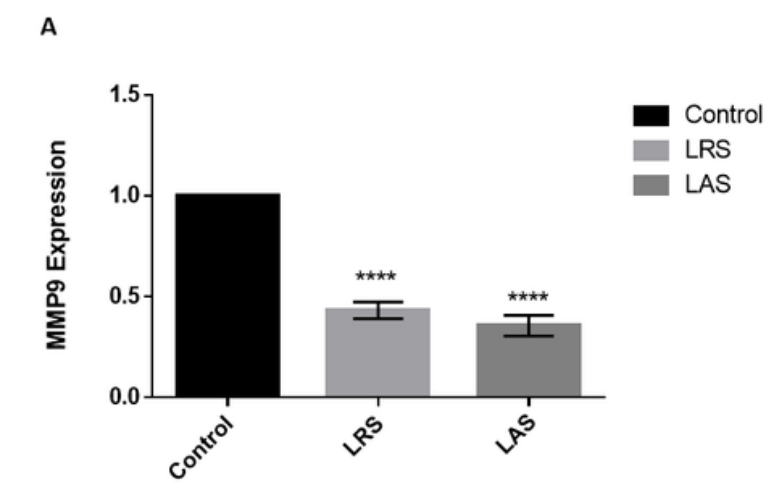

B

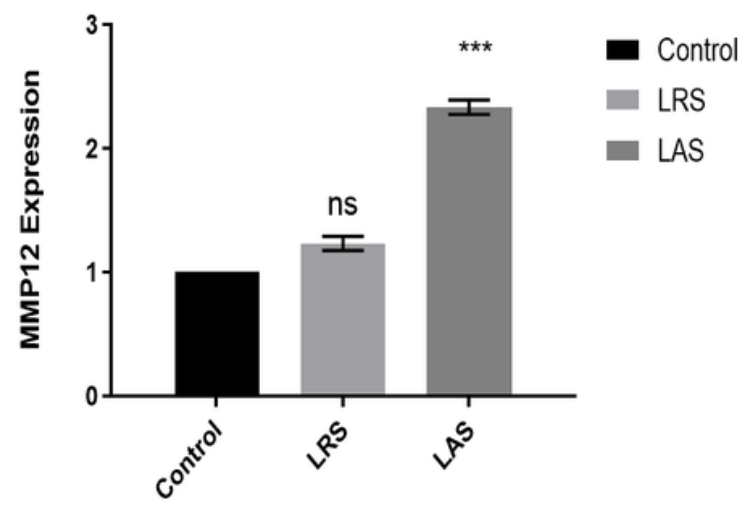

Figure 4 
The impact of LAS and LRS on the expression of MMP-12 and MMP-9 genes. A. The effects of MRS, LAS, and LRS on the expression of the MMP-12 gene. B. The effects of MRS, LAS, and LRS on the expression of the MMP-9 gene in $\mathrm{Caco} 2$ cells. The relative expression analysis of target genes was performed by the $2-\Delta \Delta \mathrm{Ct}$ method. The values are expressed as the means \pm SD from three independent experiments. * $P<0.05, * * ; P<0.01, * \star * ; P<0.001, * \star \star * ; P<0.0001$. 